\title{
Conflitos na gestão do Parque Nacional da Serra da Bocaina: entraves ao desenvolvimento local na vila de Trindade (Paraty, RJ)
}

Conflicts in the management of the National Park Serra da Bocaina: obstacles to local development in the village of Trindade (Paraty, Rio de Janeiro)

Les conflits dans la gestion du Parc National de Serra da Bocaina: lesobstacles au développement local dans le village de Trindade (Paraty, Rio de Janeiro)

Conflictos en la gestión del Parque Nacional Serra da Bocaina: obstáculos para el desarrollo local en el pueblo de Trindade (Paraty, Río de Janeiro)

\author{
Bruna Ranção Conti* \\ Diogo de Carvalho Antunes**
}

Recebido em 5/5/2011; revisado e aprovado em 13/11/2011; aceito em 28/3/2012

\begin{abstract}
Resumo: Este trabalho tem por objetivo evidenciar os conflitos socioambientais presentes na gestão do Parque Nacional da Serra da Bocaina, na área da vila de Trindade, e destacar as contradições entre as lógicas de desenvolvimento implícitas nesse processo. O estudo se insere no debate sobre as velhas e novas concepções de desenvolvimento, com foco na gestão de unidades de conservação. A partir da experiência apresentada, constata-se que ainda é preciso avançar na integração entre sociedade e natureza e na descentralização da gestão dessas áreas. Palavras-chave: Desenvolvimento. Conflitos socioambientais. Participação social.
\end{abstract}

Abstract: This paper aims to highlight socio-environmental conflicts triggered in the management of the National Park Serra da Bocaina at Trindade's Village. It focuses upon the contradictions present between the different views of development implicitly drawn upon during the management process. The research contributes to ongoing debates on old and new approaches to development, focusing upon the management of protected areas. Based on an analysis of this experience, the paper concludes on the need to better the integration between society and nature, as well as, promote a decentralization of management at these areas.

Key words: Development. Socio-environmental conflicts. Social participation .

Résumé: Ce document vise à souligner les conflits sociaux et environnementaux présents dans la gestion du Parc National de Serra da Bocaina dans le domaine de la village de Trindade, et de souligner les contradictions entre les vues de développement dans ce processus. L'étude s'inscrit dans le cadre du débat sur les conceptions anciennes et nouvelles de développement, en se concentrant sur la gestion des aires protégées. De l'expérience présentée, il apparaît qu'il est encore nécessaire pour faire avancer l'intégration de la nature et la société et de la décentralisation de la gestion de ces zones.

Mots-clés: Développement. Conflits socio-environnementales. Participation sociale.

Resumen: El presente trabajo tiene como objetivo destacar los conflictos socioambientales presentes en la gestión del Parque Nacional da Serra da Bocaina, en el área de pueblo de Trindade, y destacar las contradicciones existentes entre las visiones sobre el desarrollo utilizadas durante ese proceso. El estudio contribuye al debate sobre las viejas e nuevas concepciones de desarrollo, centrándose en la gestión de las áreas protegidas. Con base en la experiencia presentada, parece que todavía es necesario avanzar en la integración de la naturaleza y la sociedad y en la descentralización de la gestión de estas áreas.

Palabras clave: Desarrollo. Conflictos socioambientales. Participación social.

\section{Introdução}

A disseminação da ideia de desenvolvimento como crescimento econômico e aumento quantitativo do consumo marcou o capitalismo moderno e propiciou a superexploração dos recursos naturais em diversos países. Entretanto as consequências negativas desse modelo de desenvolvimento começaram a ser sentidas a partir dos anos 1970, o que foi bastante evidenciado pelos movimentos ambientalistas em crescente expansão. A ideia de uma crise ambiental passou a ser cada vez mais difundida, até o ponto em que ficou claro que a principal causa da crise estava relacionada ao modelo de desenvolvimento vigente. Tal perspectiva é apresentada no relatório da Comissão Mundial sobre Meio Ambiente e Desenvolvimento da ONU, intitulado "Nosso Futuro Comum", de 1987. Nesse relatório,

* Doutoranda em Políticas Públicas, Estratégias e Desenvolvimento (PPED/UFRJ). Turismóloga. Pesquisadora do Instituto Nacional de Ciência e Tecnologia em Políticas Públicas, Estratégias e Desenvolvimento. E-mail: bruna-conti@hotmail.com ** Mestrando em Políticas Públicas, Estratégias e Desenvolvimento (PPED/UFRJ). Cientista Social. Pesquisador do Instituto Nacional de Ciência e Tecnologia em Políticas Públicas, Estratégias e Desenvolvimento. E-mail: diogocantunes@gmail.com 
foi apresentada a ideia de desenvolvimento sustentável, que a princípio se concentrou na questão ambiental, com o objetivo de garantir a satisfação das necessidades presentes sem comprometer a capacidade das gerações futuras de suprir suas próprias necessidades. A partir da década de 80, inicia-se também o debate sobre o conceito de desenvolvimento humano, no âmbito do Programa das Nações Unidas para o Desenvo1vimento (PNUD). Nesse conceito, o desenvolvimento é entendido como um processo capaz de ampliar tanto as oportunidades dos indivíduos nas áreas da economia, da política e da cultura, quanto os níveis de bem-estar (PNUD, 1998).

A discussão sobre desenvolvimento também tem avançado em outros aspectos. Entre os novos desafios que se apresentam, incluem-se, além da instauração de uma relação mais harmônica entre sociedade e natureza, com um padrão de produção e consumo diferente do observado no capitalismo moderno, a expansão das liberdades substantivas dos cidadãos (SEN, 2000), com o consequente aprofundamento da democracia; o fortalecimento do papel do Estado como defensor dos bens de interesse comum; e a repartição mais equitativa dos recursos econômicos (DINIZ, 2010). Em virtude dessas mudanças, as novas políticas públicas devem cada vez mais priorizar ações em conjunto com a sociedade civil, pois precisam se basear em projetos abrangentes, sustentáveis, com objetivos comuns definidos, visão e acompanhamento de longo prazo (EVANS, 2010). Nessa nova lógica, um conceito que vem sendo bastante utilizado na literatura é o de desenvolvimento local, no qual se destaca o pressuposto da organização da sociedade civil em nível local para a viabilização de empreendimentos comunitários e a gestão sustentável dos recursos comuns.

No Brasil, a política ambiental foi pioneira ao incorporar, em suas bases conceituais, alguns dos aspectos dessa nova visão de desenvolvimento, principalmente no que diz respeito à importância do papel do Estado na coordenação dos interesses sociais diversos e à necessidade da criação de instâncias participativas para a tomada de decisão. Tais características estão claramente expressas na Política Nacional do Meio Ambiente (Lei n. $6.938 / 81)$. Esse documento previa que o processo decisório referente à gestão ambiental deixasse de se basear em decisões unilaterais da autoridade pública para estabelecer canais de negociação e decisão junto à sociedade civil (CARVALHO, 2005). Vale ressaltar que a necessidade de mecanismos de participação previstos nessa nova política foi também influenciada por uma conjuntura de efervescência da cidadania a nível nacional, marcada pelo enfraquecimento da ditadura militar e pelo fortalecimento dos movimentos sociais e de redemocratização do país.

Nos últimos anos, a legislação ambiental brasileira vem avançando na constituição de mecanismos que possibilitem a participação social na lógica de governança ${ }^{1}$ democrática, o que fica evidente na gestão de áreas protegidas (AP) - áreas demarcadas para a proteção in situ que se tornaram, recentemente, um dos principais meios para a proteção da natureza em todo o mundo. Diante da crescente necessidade de proteção das florestas, foi negociada, no âmbito da Rio- $92^{2}$, a Convenção da Diversidade Biológica, tendo como um dos seus objetivos o de possibilitar uma gestão integrada das AP existentes em diversos países. A Convenção estabeleceu que os países signatários deveriam desenvolver processos planejados de uso sustentável da diversidade biológica, através da instituição de sistemas de proteção da natureza que possibilitassem uma melhor administração dessas áreas e incentivassem a participação de comunidades locais em sua gestão.

Assim, no Brasil, após um longo processo de discussão e embates, foi criado, em 2000, o Sistema Nacional de Unidades de Conservação (SNUC), como um esforço de integração entre sociedade e natureza em políticas públicas, consolidando o compromisso de participação social para o alcance do desenvolvimento sustentável. O SNUC avança

\footnotetext{
${ }^{1}$ Para Graham et al. (2003 apud IRVING, 2010, p. 143) governança se refere "à interação entre estruturas, processos e tradições, que determina como o poder e as responsabilidades são exercidos, como decisões são tomadas e como os cidadãos e outros parceiros envolvidos (stakeholders) são ouvidos".

${ }^{2}$ A Rio-92 foi a Conferência das Nações Unidas sobre o Meio Ambiente e o Desenvolvimento (CNUMAD), realizada entre 3 e 14 de junho de 1992 no Rio de Janeiro. O seu objetivo principal era buscar meios de conciliar o desenvolvimento socioeconômico com a proteção dos ecossistemas. Nesta conferência ficou consagrado o termo "Desenvolvimento Sustentável".
} 
no sentido de assegurar os mecanismos e procedimentos necessários à participação efetiva das populações locais na criação, implantação e gestão das unidades de conservação ${ }^{3}$ (UC). O SNUC expressa também a necessidade de articulação entre as políticas públicas de proteção da natureza e as políticas vinculadas à promoção do desenvolvimento econômico e social local, e a necessidade de se promover a utilização dos princípios e práticas de conservação da natureza no processo de desenvolvimento (IRVING, 2010).

No entanto, apesar dos avanços nesse arcabouço legal com relação aos mecanismos de participação social e governança democrática, na prática, a implementação de tais propostas tem enfrentado uma série de conflitos. Tais conflitos são derivados, a princípio, de uma lógica de cisão entre sociedade e natureza, correspondente ao padrão insustentável de desenvolvimento já citado, que desencadeou a necessidade de isolamento de determinados espaços naturais, tanto para a proteção, quanto para proporcionar áreas de lazer. Tal lógica, representada no Brasil pelas categorias de UCs de proteção integral, levou à exclusão de populações humanas residentes nesses espaços e à imposição de várias restrições de uso dos recursos naturais, desencadeando uma série de entraves ao desenvolvimento local e ocasionando diversos "conflitos socioambientais". Esse conceito é discutido por Acserald (2004), para quem os conflitos envolvem:

grupos sociais com modos diferenciados de apropriação, uso e significação do território, tendo origem quando pelo menos um dos grupos tem a continuidade das formas sociais de apropriação do meio que desenvolvem ameaçada por impactos indesejáveis [...] decorrentes do exercício das práticas de outros grupos (ACSERALD, 2004, p. 26).

Chega-se então a um paradoxo: como seria possível a incorporação das populações locais na criação e implementação de áreas protegidas - denotando uma nova concepção de desenvolvimento - se lhes é retirado o direito de manutenção de seu modo de vida e atividades tradicionais, através da impossibilidade de acesso aos recursos naturais?

\footnotetext{
3 Esta nova terminologia passou a ser utilizada para designar o conjunto de AP contempladas pelo sistema.
}

Tal problemática pode ser observada, na prática, no processo de reestruturação da gestão do Parque Nacional da Serra da Bocaina (PNSB) a partir de 2008, o qual constitui o estudo de caso aqui apresentado. Tendo em vista a abrangência e importância do Parque, o recorte desta pesquisa se concentra na vila de Trindade, uma vila de pescadores que se encontra parcialmente no interior do PNSB e que atualmente vive uma série de conflitos com a administração da unidade para a viabilização do seu desenvolvimento.

Diante do exposto, o presente trabalho tem por objetivo evidenciar os conflitos socioambientais presentes na gestão do Parque Nacional da Serra da Bocaina na área da Trindade e destacar as contradições entre as lógicas de desenvolvimento implícitas nesse processo.

A hipótese do trabalho é que o estabelecimento efetivo de uma nova lógica de desenvolvimento na área do PNSB é impossibilitado por conflitos inerentes a uma lógica de cisão sociedade-natureza e a um estilo centralizador na gestão dos recursos comuns presentes nesse território.

No plano metodológico, a pesquisa se baseou em revisão bibliográfica, além de uma pesquisa de campo ${ }^{4}$, envolvendo entrevistas semiestruturadas dirigidas a representações da população local de Trindade e da gestão pública da UC. As mesmas foram realizadas em julho de 2010, compreendendo sete interlocutores locais identificados por meio da técnica de "bola de neve" e três interlocutores institucionais ${ }^{5}$. A partir de análise qualitativa, com foco nos conflitos socioambientais, são discutidos alguns resultados obtidos, importantes subsídios para a compatibilização entre a gestão dessa área protegida e o desenvolvimento local da vila de Trindade.

Na próxima sessão, é apresentado o referencial teórico do trabalho, centrado na discussão sobre o processo de implementação de

\footnotetext{
${ }^{4}$ Essa pesquisa de campo foi realizada no âmbito da dissertação de mestrado da autora Bruna Ranção Conti (2011), denominada "Proteção da natureza e qualidade de vida em Trindade (Paraty-RJ): para entender o ecoturismo no Parque Nacional da Serra da Bocaina".

${ }^{5}$ Todos os entrevistados assinaram termos de consentimento livre e esclarecido, permitindo a utilização, para fins acadêmicos, das informações obtidas na pesquisa.
} 
unidades de conservação no Brasil. Na sessão dois, é descrito o estudo de caso, sobre o qual se baseia o artigo. Na sessão posterior, serão expostas e analisadas as visões dos moradores da Trindade e dos administradores do PNSB com relação ao processo de implementação e gestão do Parque. Por fim, a sessão quatro é dedicada à discussão e às considerações finais do trabalho.

\section{Os conflitos resultantes do processo de implementação de UCs no Brasil}

Para se entender os motivos pelos quais os conflitos socioambientais são inerentes à criação e gestão das unidades de conservação brasileiras, é importante destacar que essa política é derivada de um modelo formulado na América do Norte, que prevê que a proteção dos recursos naturais só poderia ser garantida se estes fossem deixados livres da ação humana (DIEGUES, 2004). Sendo assim, no caso brasileiro, a implantação desse modelo tem sido fonte de inúmeros conflitos socioambientais, principalmente no interior ou entorno de Parques, categoria de UC de proteção integral que representa um exemplo emblemático de cisão sociedade-natureza. Com relação a essa questão, Diegues argumenta ainda que esses conflitos se agravam quando a criação e a implementação dessas "ilhas" de proteção da natureza se efetuam de forma autoritária e pouco negociada pelo Estado com os diferentes segmentos locais, entendidos como "transgressores" da lei. Diante dessa situação, o autor afirma que o modelo de criação de Parques tem sido alvo de muita discussão e polêmica, principalmente no que diz respeito à manutenção das populações tradicionais em seu interior e às possibilidades de desenvolvimento em seu território.

Os mecanismos de participação social poderiam representar um contraponto a esse legado centralizador na criação das UCs. Nesse âmbito, um dos primeiros documentos nacionais de política pública que avançam na consolidação de uma nova atitude do Estado na sua relação com a sociedade é o Sistema Nacional de Unidades de Conservação. Dentre esses mecanismos, evidenciam-se: a garantia de meios de subsistência alternativos às populações locais que dependem da utilização dos recursos naturais existentes no interior dessas UCs, a valorização do conhecimento tradicional, a promoção da educação ambiental e, principalmente, a criação e fortalecimento dos conselhos de gestão paritários (BRASIL, 2000).

Para Diegues (2004), Bensusan (2006) e Irving e Matos (2006), é inegável o avanço que se processou no Brasil em relação à temática da proteção da natureza com a instituição do SNUC, mas esses autores também destacam que existem ainda muitos problemas para a consolidação efetiva das áreas protegidas brasileiras, como a falta de planejamento a longo prazo, a ausência de grandes contingentes de pessoas para fiscalizar as áreas, o aporte ainda limitado de recursos financeiros para o processo, os conflitos com as populações humanas que vivem no interior e no entorno dessas áreas e a necessidade de fazer com que essas áreas se tornem arenas de transformação social, contribuindo para a expansão das liberdades e das capacidades humanas, conforme a visão de desenvolvimento humano (SEN, 2000).

Tendo em vista essa dinâmica, pode-se afirmar que a política brasileira de implantação de UCs tem sido incoerente. Isso acontece porque, dentro da mesma política, estão contempladas uma nova e uma velha lógica de desenvolvimento. A nova lógica está presente nos princípios da política, que preveem a participação social como ponto fundamental para a ação estatal. Porém esses princípios acabam sendo sobrepujados, na prática, pelo estilo de gestão tecnocrático e centralizador, herdado das concepções de desenvolvimento do século passado ${ }^{6}$.

Quando se observa a gestão do Parque Nacional da Serra da Bocaina na vila de Trindade, percebe-se a presença dessas duas lógicas de desenvolvimento. Ao mesmo tempo em que a gestão busca avançar em mecanismos de participação, a maioria das suas ações ainda acontece de uma maneira impositiva e descolada da realidade local, o que desencadeia uma série de conflitos.

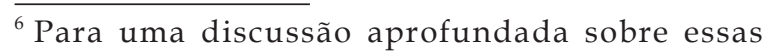
diferentes concepções de desenvolvimento, ver Evans (2010).
} 


\section{O Parque Nacional da Serra da Bocaina e a vila de Trindade}

O Parque Nacional da Serra da Bocaina foi criado em 1971, localiza-se na divisa entre os Estados de São Paulo e Rio de Janeiro e está inserido em importantes municípios turísticos como: Angra dos Reis, Paraty, Ubatuba, Cunha, Areias, São José do Barreiro e Bananal (BRASIL, 2002). Em função da beleza cênica dos vários pontos turísticos do Parque, como as cachoeiras nas serras, as praias do litoral e as fazendas históricas nas cidades do Vale do Paraíba do Sul, várias trilhas e caminhos em seu interior têm sido explorados pelo turismo regional. Os atrativos naturais e históricos do entorno da área também são, de certa forma, indutores do uso turístico do Parque.

$\mathrm{O}$ recorte desta pesquisa se concentra na vila de Trindade, um núcleo de pescadores parcialmente localizado no interior do PNSB. Essa vila pertence ao Distrito de Paraty-Mirim (no município de Paraty), que compreende $40 \%$ do Parque, uma das áreas com maior atratividade turística na região da denominada Costa Verde. Essa localidade encontra-se a $22 \mathrm{~km}$ do centro de Paraty, é cercada pela Mata Atlântica, em parte no interior da Área de Proteção Ambiental (APA) Cairuçu e do PNSB. Essa localidade possui cinco grandes atrativos naturais no entorno ou interior da área do Parque: as Praias Brava, dos Ranchos, do Meio, do Caixadaço e a Piscina Natural do Caixadaço, além das várias trilhas e cachoeiras, fatores que impulsionam um grande número de visitações. Porém sua vila de moradores encontra-se no entorno direto do Parque e no interior da APA.

A história da vila de Trindade se associa à luta dos moradores para permanecerem no local. Essa luta começou em 1970, quando a multinacional Brascan tentou construir na vila um condomínio de luxo, passando a comprar terras dos nativos. Como muitos se recusaram a deixar suas casas, a empresa enviou para a área jagunços armados, reclamando o direito de posse da terra, destruindo as poucas construções existentes e desabrigando moradores (PEREIRA, 2001).

Em Laranjeiras, próximo à Trindade, a mesma multinacional construiu o luxuoso Condomínio de Laranjeiras, um dos mais exclusivos do país. Nessa região, ao contrário do que ocorreu na vila, não houve luta pela terra (OLIVEIRA, 2005).

A população de Trindade conseguiu garantir o direito à terra na justiça ${ }^{7}$, através da ajuda de alguns turistas que frequentavam a vila. Estes instruíram e apoiaram os moradores nesse movimento, fortalecendo a divulgação da invasão da área nas mídias nacional e internacional, contando também com o apoio de um grande jurista ${ }^{8}$. Foi devido a essa articulação entre visitantes e população local que a vila não foi substituída pelo empreendimento. Em 1981, foi estabelecido um acordo entre a multinacional e os habitantes locais, segundo o qual, grande parte das terras ainda permaneceria sob o poder da primeira. Porém, além do direito a terra, os nativos conquistaram a garantia da liberdade de acesso às praias (OLIVEIRA, 2005).

Somente após a construção do condomínio Laranjeiras foi implantada a rodovia PRT-101 (popularmente conhecida como Morro do Deus-me-livre), único acesso regular à vila de Trindade. Em 1999, a pavimentação dessa estrada e a chegada da telefonia à vila contribuíram para o aumento considerável do fluxo de visitantes no local, o que ocasionou a atração de empreendedores de diversas localidades. Assim, como enfatiza Pereira (2001), as casas de veraneio, pousadas, restaurantes e bares, construídas de modo desorganizado, "concorreram com as práticas comerciais dos nativos, aumentando o impacto de desordem social já bastante grave entre os nativos e novos residentes lá estabelecidos". Nesse percurso, Oliveira (2005) afirma que grande parte da população da vila de Trindade, assim como diversas áreas do município de Paraty, vem sofrendo um processo de marginalização resultante do "desenvolvimento" proporcionado pelo turismo. A chegada da urbanização, a partir dos anos 70, significou o começo da era do

\footnotetext{
${ }^{7}$ A partir desse momento, a população local se organizou em uma Associação de Moradores Nativos e Originários de Trindade (AMOT). Atualmente, a Associação tem como principais focos o turismo, devido a sua importância para a economia local, e a busca por investimentos em infraestrutura urbana na vila. Além disso, a Associação é o canal de comunicação com os representantes do poder público.

${ }^{8} \mathrm{O}$ Dr. Sobral Pinto, que atualmente dá nome à rua principal de Trindade.
} 
"des-envolvimento", entendido como antítese de envolvimento. Até então, as populações caiçaras tinham uma vida adaptada às características das florestas, rios e mares das suas regiões, constituindo uma integração intensa com a natureza.

Luchiari (2000) aponta que esse modelo economicista do desenvolvimento constitui um dos principais obstáculos para a promoção da participação efetiva de todos os atores sociais nos projetos de turismo. Porém a autora afirma que, segundo uma nova ordem mundial de desenvolvimento, em busca da sustentabilidade econômica, ambiental e sociocultural, o turismo passa a exigir a atribuição de novos papéis à população local e uma política de inclusão, principalmente em áreas mais sensíveis. A análise sobre essas questões incentiva a adoção de uma nova forma para se pensar o desenvolvimento do turismo, pautado em uma visão mais humana que mercadológica, principalmente quando desenvolvido em áreas naturais protegidas.

Nesse contexto, apesar do desenvolvimento do turismo ter se convertido, no âmbito da política pública, como alternativa para o desenvolvimento local - o que é observado na vila de Trindade -, Benevides (2002) discute que o único meio de se promover esse desenvolvimento através do turismo seria equalizando cinco objetivos: a) preservação/ conservação ambiental, b) manutenção da identidade cultural, c) geração de ocupações produtivas de renda, d) desenvolvimento participativo, e) qualidade de vida.

\section{O processo de implementação e gestão do Parque Nacional da Serra da Bocaina}

\subsection{Como se expressa a relação de Trindade com o PNSB: a visão dos trindadeiros}

É possível afirmar que a relação entre a Trindade e o PNSB é entendida como conflituosa. Tal interpretação, por parte dos atores locais, se deve a inúmeros problemas decorrentes do processo de criação de uma UC de proteção integral em um território já ocupado por diversos habitantes que se denominam "caiçaras" ${ }^{9}$ e dependem dos recursos naturais

\footnotetext{
9 Para Diegues (2004), os caiçaras podem ser definidos como população tradicional, por se enquadrarem nas
}

ali existentes.

A "ausência do Parque" durante muitos anos na Trindade é um importante motivo de "desconfiança" com relação às intenções dos administradores dessa unidade. $\mathrm{O}$ fato de a equipe técnica do Parque, depois de mais de 30 anos de ausência na localidade ${ }^{10}$, ter a missão atual de implementar efetivamente a UC, vem causando incertezas, principalmente na parcela da população que viveu o conflito pela posse das terras com a empresa Brascan. Esses atores se mostram receosos com o fato de os administradores do PNSB definirem normas para a vida da localidade, até mesmo impedindo e/ou controlando práticas e atividades ali consolidadas. A ausência histórica dos administradores do Parque e os conflitos gerados pela falta de informação sobre os objetivos da UC e os limites de uso do território, assim como os conflitos gerados pelas atitudes de alguns administradores - consideradas autoritárias pelos trindadeiros -, estão descritos nas seguintes falas:

Olha, o Parque, o decreto é de 71, 72, e Trindade mesmo só ficou sabendo de Parque por conversas. A gente já ouvia falar de Parque Nacional da Serra da Bocaina, mas a gente nunca sabia onde era o Parque. Então o Parque é recente... O Parque ficou ausente 30 anos. Aí eles chegam e falam que o Parque é aqui e acabou (Entrevistado $\mathrm{F}$ - pousadeiro).

\footnotetext{
seguintes características: Conhecimento da natureza e seus ciclos, o que resulta em formas de manejo e uso dos recursos, reduzindo o impacto sobre o meio ambiente; $\mathrm{O}$ conhecimento é transmitido de geração em geração por meio da oralidade; Existe uma ideia de território ou espaço no qual o grupo se reproduz entre si e economicamente; Os grupos estabelecem formas de habitação e ocupação do território por gerações, mesmo sendo a mobilidade um elemento presente na sua cultura; A atividade de subsistência é um elemento presente, mesmo existindo uma relação de compra e venda de produtos; A unidade familiar é um elemento fundante da cultura; As relações de parentesco e compadrio estabelecem os parâmetros das atividades socioeconômicas e culturais. $\mathrm{O}$ trabalho artesanal é presente. $\mathrm{O}$ artesão, juntamente ou não com sua família, domina o processo produtivo até a etapa final. E por fim, as populações se caracterizam pela autoidentificação como tais.

${ }^{10}$ Esta ausência ocorreu por causa da grande extensão territorial do PNSB, da dificuldade de limitação da área da UC, da ausência de pessoal e, principalmente, em função dos graves problemas fundiários que deveriam ser enfrentados.
} 
Outros fatos que desencadearam importantes conflitos entre a população local e a administração do Parque (dificultando sua entrada na localidade) foram: a proibição do uso de uma área de camping no interior do PNSB por parte da AMOT; o embargo das obras na rede de tratamento de esgoto na vila (em andamento há 12 anos), por inexistência de licença ambiental; a possibilidade de proibição da pesca local; e a iminência da retirada dos quiosques localizados na Praia do Meio. Com relação ao primeiro fato, os atores locais advogam que o camping gerido pela Associação de Moradores representava a principal fonte de renda dessa instituição, que, por sua vez, aplicava tais recursos na própria localidade. No que diz respeito ao segundo problema, todos os entrevistados da pesquisa se mostraram contrários à posição da equipe do Parque em paralisar as obras na rede de esgoto. Se o maior objetivo de um Parque Nacional é a proteção da natureza, os trindadeiros não conseguem entender como os administradores da UC podem embargar uma obra que também tem como objetivo principal a proteção da natureza. Além disso, os atores locais alegam que, se há algum processo inadequado em curso na localidade, deveria ser função da equipe técnica do Parque trabalhar em parceria com os moradores para a resolução do problema e não definir, unilateralmente, o encaminhamento para a questão identificada.

Já com relação à pesca, todos criticam a provável proibição dessa atividade no interior da UC, apesar de os administradores alegarem bases legais para isso. Para os moradores da Trindade, a pesca representa a base da cultura caiçara ainda existente na vila e, para alguns, a base da renda familiar. Por fim, sobre a retirada dos quiosques instalados na praia do Meio, a população como um todo também percebe essa ação como desnecessária e preocupante, no que diz respeito à eliminação das possibilidades de trabalho das pessoas. Eles alegam que, se o Parque retirar esses trabalhadores da praia do Meio, será preciso oferecer condições para que estes não percam sua fonte de renda:

Na praia do meio você tem uma série de quiosques e restaurantes, e aquilo causa um impacto ambiental violento, isso todo mundo sabe, mas se você tira todos aqueles restaurantes dali, você causa um impacto social fortíssimo, porque todos ali têm como fonte de renda aqueles restaurantes (Entrevistado F - pousadeiro).

Dessa forma, as restrições ao uso dos recursos naturais renováveis vêm potencializando um processo de resistência dos atores locais à existência da UC e, a partir daí, surgem os conflitos de interesses, uma vez que as demandas de preservação da natureza se contrapõem a algumas necessidades de sobrevivência dos grupos que habitam o local. Diante desse cenário de conflitos, parecem existir duas visões distintas sobre as consequências da existência do Parque para a Trindade. Para a primeira, representada pela interpretação dos atores locais que viveram o conflito de terras com a Brascan, o Parque não irá trazer qualquer benefício para a localidade. E neste caso, os interesses da administração do PNSB estariam sintonizados com os dos proprietários particulares do vizinho Condomínio Laranjeiras, e visariam, além da proibição da pesca, o controle do número de turistas na Trindade e a retirada dos quiosques instalados na praia do Meio, com a finalidade de enfraquecer a cultura caiçara e dificultar o trabalho e a geração de renda para a população da Trindade. A segunda perspectiva resulta do grupo de moradores da Trindade que tem uma visão positiva acerca das consequências da existência do Parque. Este grupo é representado pelos mais jovens da vila. Nessa segunda abordagem, há a crença de que o Parque poderá trazer muitos benefícios para os turistas e para a população local, mesmo quando se expressa o receio com relação ao futuro.

No que diz respeito às parcerias estabelecidas entre o Parque e o condomínio Laranjeiras - quando a nova equipe do PNSB chegou a Trindade - ambos os grupos confirmam que esta relação acabou por romper com o início de uma parceria entre a administração da UC e os trindadeiros. Para esses atores, os administradores não estariam preocupados com os moradores da vila, e sim em favorecer os grandes investidores da região. Porém, atualmente, este continua sendo um problema somente para o grupo que entende o Parque como um entrave para a vida no local. Os demais atores não acreditam que a administração está interessada em trabalhar a favor 
de interesses particulares, e, sim, conseguir parcerias para o financiamento de atividades de conservação da biodiversidade.

Apesar de todas as preocupações mencionadas, o grupo que se mostra a favor da existência do Parque considera que poderá ser gerada uma série de benefícios para a população local, como a garantia do direito à posse da terra para os trindadeiros, o ordenamento do turismo na vila e a proteção da natureza. Além disso, é interessante destacar que esse grupo também associa o Parque com o resgate e fortalecimento da Associação de Moradores, o que é interpretado como um ponto positivo, gerado a partir desse processo recente de implementação da UC. Com a necessidade de maior articulação entre os moradores e o PNSB para que pudessem ser debatidos os caminhos para o desenvolvimento na vila, a Associação voltou a ter força e representatividade.

Essa aproximação e o sentido de parceria parecem reafirmar a discussão de Irving (2010, p. 134), de que

[...] a necessidade de mobilização social para a solução de problemas comuns potencializa o nível de organização comunitária e o empoderamento local, com a consequente internalização da noção de valor deste patrimônio coletivo.

Diante do contexto discutido, o caminho proposto pelos moradores da Trindade para que a implementação do Parque não ocorra de modo a prejudicar a vida dos trindadeiros é o diálogo constante entre a administração do PNSB e a população local, assim como a sua participação em todos os processos decisórios com relação à gestão da UC. Nesse sentido, parte da população local avalia que, a partir do início da última gestão, vem ocorrendo um esforço para o fortalecimento do diálogo entre a administração do Parque e os moradores. Sendo assim, para os trindadeiros não basta que os administradores apresentem regras e queiram impor um novo jeito de viver aos moradores da vila, o mais importante é que a equipe técnica da UC proporcione meios para que a população possa respeitar a legislação e continuar com suas atividades tradicionais, que são a base do seu sustento e renda. Nesse sentido, o mais importante seria entender as peculiaridades da cultura local e buscar o estabelecimento de parcerias entre os trindadeiros e o PNSB para uma efetiva implementação do Parque.
Portanto, na visão local, para que ocorra a implementação do Parque, é necessário um diálogo claro entre as instâncias envolvidas. Porém, uma das principais dificuldades para o processo de implementação e gestão das unidades de conservação, com destaque para os Parques, é justamente o fato de os órgãos governamentais dificilmente atuarem em conjunto no local de inserção de uma UC, o que gera uma atuação institucional distante da realidade local.

\subsection{Como se expressa a relação do PNSB com a Trindade: a visão dos gestores públicos}

Após mais de 30 anos de ausência na Trindade, a administração do PNSB reconhece que a implementação da UC vem ocorrendo de forma lenta, e há ainda muitos desafios a serem transpostos. Algumas ações iniciais, como a proibição da área de camping da Associação de Moradores no interior do Parque, a autuação de todos os quiosques instalados na praia do Meio, as discussões sobre a necessidade de retirada desses quiosques e a colocação de placas informativas sobre a existência do PNSB geraram tensões entre a população local e a equipe técnica da UC. É possível perceber, em algumas falas, que as regras iniciais impostas à população local sobre o que seria ou não permitido na Trindade realmente não foram construídas em parceria com os atores locais, o que gerou ainda mais conflitos:

Nós estabelecemos algumas normas, que não foram construídas junto com a comunidade. Nós chegamos estabelecendo o que não podia mais acontecer $\mathrm{e}$ foi um processo que primeiro teve uma reação muito forte, teve trindadeiro que atravessou a sala, colocou o dedo na minha cara e disse que eu ia ter que matar ele para fechar o camping (Interlocutor 1 - chefe do PNSB).

Apesar dos problemas iniciais, a equipe da UC considera Trindade como uma das áreas focais que mais tem exigido a atenção da administração do Parque. Isto porque, apesar desta ser uma área não muito extensa, se comparada com toda a área do Parque, ela possui uma visibilidade elevada. Para os administradores, ações como a demarcação da unidade, com a instalação de cercas e placas informativas, operações de fiscalização, elabo- 
ração de termos de compromisso, a proibição da pesca e o ordenamento do turismo na vila são primordiais para a implementação do PNSB na área da Trindade.

Um item central para a equipe técnica é a demarcação da área do Parque, para que se evite alegações de desconhecimento dos limites da UC pela população local. Para a administração do PNSB, mesmo ainda não sendo clara essa delimitação, todos os proprietários de posses ilegais não podem alegar desconhecer que estão no interior de uma unidade de conservação de proteção integral, já que, mesmo antes do início da implementação efetiva do Parque, todos já haviam sido autuados.

No que diz respeito especificamente às famílias que vivem no interior da área do Parque desde antes de sua criação, a equipe do PNSB optou pela elaboração de um Termo de Compromisso para normatizar as atividades que vêm sendo realizadas para atender aos turistas como, por exemplo, a regularização dos campings. Sendo assim, a intenção é firmar acordos individuais com esses moradores, garantindo a manutenção de suas famílias no local até que elas sejam indenizadas.

Vale lembrar que o Decreto 4.340, de agosto de 2002 (em seu artigo 39), que visa regulamentar alguns artigos da Lei do SNUC, menciona que, no caso de populações tradicionais em UCs de proteção integral, "enquanto estas não forem reassentadas, as condições de permanência serão reguladas por um Termo de Compromisso, negociado entre o órgão executor e as populações, ouvido o Conselho da unidade de conservação" (BRASIL, 2000). Pela legislação vigente, na elaboração do Termo de Compromisso, deverão ser indicadas as áreas ocupadas, as limitações necessárias para assegurar a conservação da natureza e os deveres do órgão executor em relação ao processo indenizatório, devendo ser assegurados o acesso das populações às suas fontes de subsistência e a conservação dos seus modos de vida. A partir do exposto nesse decreto, Melo (2007) discute que a grande ironia em torno da gestão, no caso dos Parques Nacionais, é que às populações locais é permitido participar do planejamento da própria exclusão, já que para o Termo de Compromisso ser firmado entre atores locais e institucionais, o processo de indenização e retirada dessa população local precisa estar explicitado.
Importante considerar, então, que as questões de indenização não são as únicas que precisam ser avaliadas no momento de retirada da população local para implementação do Parque. Questões relativas aos impactos sociais e culturais também devem ser melhor entendidas, pela administração da UC, como essenciais nessa negociação.

Com relação à pesca, a atividade vem também ocorrendo em desacordo com as normas da UC, mas esse tema ainda não é prioridade para a administração do PNSB, uma vez que ainda não há uma relação de confiança entre os atores locais e administradores do Parque, como afirma um dos entrevistados:

[...] a pesca é uma atividade que ocorre lá em desacordo com as normas do Parque, mas que a gente ainda não começou a trabalhar porque precisamos primeiro ter essa relação de confiança e construção coletiva com a comunidade (Interlocutor 1 - chefe do PNSB).

Diante desse cenário, para a equipe do Parque, a população de Trindade tem duas diferentes posições frente à UC; um desses grupos agiria a favor da existência e implementação do PNSB e teria maior consciência da necessidade de conservação e "qualificação" do turismo; enquanto o outro grupo agiria em repúdio às atividades realizadas pela equipe do Parque. A equipe do Parque atribui tal desconfiança ao fato de os trindadeiros terem vivido um processo histórico violento de luta pela posse das terras na Trindade.

Mesmo diante de um grupo que rejeita a existência da UC, o chefe do PNSB acredita que, à medida que os resultados do trabalho forem aparecendo, a população local tenderá a apoiar, cada vez mais, a administração do PNSB. A equipe técnica do Parque acredita ser possível uma medida para a minimização dos conflitos com os moradores por meio de uma maior participação da população na gestão do PNSB e a realização de atividades efetivas de educação ambiental. Assim, a administração acredita que o fortalecimento do Conselho Consultivo do Parque ${ }^{11}$ é fundamental para possibilitar essa maior participação dos atores locais na gestão e sensibilização destes para as

\footnotetext{
${ }^{11}$ A criação do Conselho Consultivo do PNSB foi oficializada após a realização das entrevistas com os administradores do Parque, pela Portaria n. 103 de 30 de setembro de 2010.
} 
necessidades de proteção da natureza. Nesse sentido, o Conselho do PNSB representa, em tese, uma instância potencial para a representação e participação da sociedade no processo, e uma via importante na discussão dos diferentes interesses envolvidos, intermediação de conflitos, mudanças sociais e democratização das relações de poder entre as populações locais e a administração do Parque.

\section{Discussão e considerações finais}

Parece haver, por parte dos dois grupos pesquisados, o reconhecimento de que a relação entre eles é marcada por uma série de conflitos. Após muitos anos de ausência da administração do Parque na Trindade, esses conflitos surgiram das ações de ordenamento do turismo e implementação do Parque. As restrições de uso e sua imposição aos grupos locais costumam ocorrer sem explicações e/ ou compensações, o que gera inúmeras frustrações e incertezas. Além disso, frequentemente, os administradores dessas áreas não percebem com clareza, no cotidiano da gestão, os conflitos sociais e culturais que tal processo costuma causar, o que se ilustra claramente na dinâmica discutida no caso do PNSB.

A partir dessa análise sobre o modelo de UCs e especialmente de Parques Nacionais adotados pelo Brasil, o caso abordado ilustra uma situação histórica de afastamento entre a gestão pública e a população local, decorrente ainda de uma velha lógica de desenvolvimento, pautada no raciocínio de que o governo sempre sabe o que é melhor para a população. Assim, o PNSB é internalizado pelos atores locais não como patrimônio coletivo, mas como bem de domínio do poder público.

Em contrapartida a essa velha lógica de desenvolvimento, parece ser reconhecida a necessidade do diálogo constante e uma maior participação dos moradores da Trindade na gestão da área. Como meio de promoção da participação, a equipe do Parque acredita na consolidação do Conselho Consultivo, criado recentemente. Não obstante, são ainda inúmeros os desafios a serem enfrentados para que o Conselho do PNSB possa realmente se transformar em espaço de governança democrática, a começar pela mobilização dos moradores locais e internalização, por ambas as partes, das dificuldades do processo. Além disso, é importante ter em mente o real alcance dos conselhos, visto que eles se inserem em campos de forças, sendo diretamente influenciados pela dinâmica sociocultural e política da região de inserção de cada UC (IRVING; MATOS, 2006). Brandão (2007) também destaca que a valorização das arenas locais não pode perder de vista os conflitos políticos e a estruturação das classes sociais presentes em uma sociedade. Dessa forma, é possível que os conselhos tenham pouca efetividade em equilibrar os interesses entre os grupos representados ou de fazer valer as decisões adotadas em favor daqueles de menor poder político, econômico e ideológico. Fica então evidente o papel do Estado em promover oportunidades equânimes de participação dentro das arenas deliberativas e atuar de maneira efetivamente coordenada, levando sempre em consideração as decisões tomadas em conjunto.

Diante desse cenário, é possível afirmar que, para o estabelecimento efetivo de uma nova lógica de desenvolvimento na gestão de unidades de conservação é preciso avançar tanto na estrutura institucional da política que ainda pressupõe, em certos casos, a impossibilidade de integração entre sociedade e natureza -, quanto na sua implementação, através da mobilização e capacitação dos gestores públicos para a governança democrática em prol de um desenvolvimento local sustentável.

\section{Referências}

ACSELRAD, H. As Práticas espaciais e o campo dos conflitos ambientais. In: Acselrad H. (Org). Conflitos ambientais no Brasil. Rio de Janeiro: Relume Dumara; Fundação Heinrich Boll, 2004.

BENEVIDES, I. P. Planejamento governamental, produtos e territorialidades turísticos no Ceará. In: ENCONTRO NACIONAL DE TURISMO COM BASE LOCAL, 6., 2002, Campo Grande. Anais... Campo Grande: [s.l.], 2002. p. 21.

BENSUSAN, N. A conservação da biodiversidade em áreas protegidas. Rio de Janeiro: FGV, 2006.

BRANDÃO, C. Território e desenvolvimento: as múltiplas escalas entre o local e global. Campinas: UNICAMP, 2007.

BRASIL. Lei 9.985, de 18 de julho de 2000. Regulamenta o art. 225, § $1^{\text {o }}$, incisos I, II, III e VII da Constituição Federal, institui o Sistema Nacional de Unidades de Conservação da Natureza e dá outras providências. Disponível em: <http://www.planalto.gov.br/ccivil_03/ leis/L9985.htm>. Acesso em: 14 out. 2011. 

desenvolvimento local na vila de Trindade (Paraty, RJ)

. Ministério do Meio Ambiente/IBAMA/DIREC. Plano de manejo do Parque Nacional da Serra da Bocaina: encarte n. 5. Brasília: FEC/UNICAMP, 2002.

CARVALHO, J. C. A vocação democrática da gestão ambiental brasileira e o papel do Poder Executivo. In: TRIGUEIRO, A. (Coord.). Meio ambiente no século 21. Rio de Janeiro: Sextante, 2005.

CONTI, B. R. Proteção da natureza e qualidade de vida em Trindade (Paraty-RJ): para entender o ecoturismo no Parque Nacional na Serra da Bocaina. Dissertação (Mestrado em Psicossociologia de Comunidades e Ecologia Social) - Programa EICOS, Instituto de Psicologia, Universidade Federal do Rio de Janeiro, Rio de Janeiro, 2011.

DIEGUES, A. C. S. O mito moderno da natureza intocada. 4. ed. São Paulo: Hucitec; Núcleo de Apoio à Pesquisa sobre Populações Humanas e Áreas Úmidas Brasileiras, USP, 2004.

DINIZ, E. Estado, variedades de capitalismo e desenvolvimento em países emergentes. Desenvolvimento em Debate. Rio de Janeiro, v. 1, n. 1, p. 7-27, jan.-abril, 2010.

EVANS, Peter. Constructing the $21^{\text {st }}$ century developmental state: potentialities and pitfalls, 2010.

IRVING, M. A. Áreas protegidas e inclusão social: uma equação possível em políticas públicas de proteção da natureza no Brasil? Sinais Sociais, Rio de Janeiro, v. 4, n. 12 , p. $122-147,2010$
IRVING, M. A.; MATOS, K. Gestão de parques nacionais no Brasil: projetando desafios para a implementação do Plano Nacional Estratégico de Áreas Protegidas. Floresta e Ambiente, Rio de Janeiro, v. 13, n. 2, p. 89-96, 2006.

LUCHIARI, M. T. D. P. O. Lugar no mundo contemporâneo: turismo e urbanização em Ubatuba-SP. Dissertação (Doutorado) - Insituto de Filosofia e Ciências Humanas, Universidade Estadual de Campinas (IFCHUNICAMP), Campinas, 2000.

MELO, G. M. A leitura da gestão dos parques nacionais sob a ótica das populações locais: os parques Montanhas de Tumucumaque e Cabo Orange. 2007. Dissertação (Mestrado em Psicossociologia de Comunidades e Ecologia Social) - Universidade Federal do Rio de Janeiro (UFRJ/ IP/EICOS), Rio de Janeiro, 2007.

OLIVEIRA, A. C. Turismo em áreas "menos desenvolvidas": caracterização, desenvolvimento e planejamento turístico da vila de Trindade, município de Paraty/ Rio de Janeiro - Brasil. Pasos - Revista de Turismo y Patrimônio Cultural. Tenerife, v. 3, n. 1, p. 149-169, 2005.

PEREIRA, Francine Maria. Vila da Trindade, Paraty, RJ: Turismo Sustentável? Santo André: Uni ABC, 2001.

Programa das Nações Unidas para o Desenvolvimento (PNUD). Projeto Desenvolvimento Humano no Brasil com a participação do IPEA, FJP e IBGE. Desenvolvimento humano e condições de vida: indicadores brasileiros. Brasília, 1998.

SEN, A. Desenvolvimento como liberdade. São Paulo: Companhia das Letras, 2000. 